\title{
QUEIMADAS CONTROLADAS E INCÊNDIOS FLORESTAIS NO ESTADO DE SERGIPE, BRASIL, ENTRE 1999 E 2015
}

\author{
Benjamin Leonardo Alves White ${ }^{1 *} ;$ Larissa Alves Secundo White ${ }^{2}$ \\ ${ }^{1}$ Universidade Federal de Sergipe, Departamento de Biociência, Itabaiana, Sergipe, Brasil - benjmk@ hotmail.com* \\ ${ }^{2}$ Universidade Federal de Sergipe, Departamento de Engenharia Florestal, São Cristóvão, Sergipe, Brasil - larissawhite@hotmail.com
}

Recebido para publicação: 06/06/2016 - Aceito para publicação: 11/10/2016

\begin{abstract}
Resumo
As queimadas controladas e incêndios florestais de grande porte respondem por impactos negativos ao meio ambiente, ocasionando danos à fauna e flora e contribuindo com a liberação de gases na atmosfera responsáveis pelo efeito estufa. Sendo assim, faz-se necessária a análise de suas distribuições espaciais e temporais a fim de aperfeiçoar e desenvolver metodologias de prevenção e combate ao fogo. Este trabalho teve por objetivo fazer uma análise dos focos de calor registrados nos municípios do estado de Sergipe, através dos satélites de referência do INPE para o período de 1999 a 2015, e correlacionar esses dados com as variáveis independentes: área de pastagem; área agrícola; área florestal; área total; precipitação anual média; população; e densidade demográfica. Também buscou-se propor um sistema de classificação da incidência de queimadas controladas e incêndios florestais. Com base nos resultados obtidos, foi observada uma tendência de alta nos registros de focos de calor ao longo dos anos. Os meses com maior ocorrência foram, respectivamente, Janeiro, Fevereiro, Março. Dentre as variáveis independentes analisadas, a área total do município, área de pastagem, área florestal, área agrícola e precipitação anual média apresentaram, em ordem decrescente de significância, correlação significativa com o número de registro de focos de calor para cada município. As variáveis população e densidade demográfica não apresentaram correlação significativa. $\mathrm{O}$ município com maior registro de focos de calor foi Tobias Barreto, enquanto que Canhoba foi o que apresentou, proporcionalmente, maior incidência por área. A relação entre a média anual de focos de calor pela área do município foi utilizada para o estabelecimento de um sistema de categorização de incidência de queimadas controladas e incêndios florestais.

Palavras-chave: Focos de calor; detecção por satélite; prevenção.
\end{abstract}

\begin{abstract}
Wildland fires between 1999 and 2015 in the State of Sergipe, Brazil. Wildland fires are responsible for negative impacts on the environment, causing damage to the fauna and flora and increasing the release of greenhouse gases. Thus, it is necessary the analysis of their spatial and temporal distribution in order to improve and develop new methods of fire prevention. This study aims to analyze the number of hot spots recorded in the municipalities of Sergipe state through data from INPE reference satellites for the period of 1999-2015, and to correlate it with the independent variables: pasture area; agriculture area; forestry area; total area; average annual rainfall; population; and population density. It also sought to propose a classification system established on the wildland fire occurrence. Based on the results, an uptrend was found in the number of hot spots recorded over the years. The months with the highest occurrence were, respectively, January, February and March. The independent variables: total area, pasture area, forestry area, agriculture area, and the average annual precipitation (in descending order of significance) correlated significantly with the number of hot spots recorded for each municipality. The variables population and population density showed no significant correlation. The municipality with the highest number of hot spots detected was Tobias Barreto, while Canhoba presented the highest incidence per $\mathrm{km}^{2}$. The mean annual hot spots detected per area was used to propose a classification criteria used for ratting wildland fire occurrence. Keywords: Hot spots; satellite detection; fire prevention.
\end{abstract}

\section{INTRODUÇÃO}

Quando o fogo queima uma determinada vegetação, o mesmo pode ser classificado como incêndio florestal ou queimada controlada. Caso o mesmo esteja sendo utilizado como forma de manejo em atividades agropastoris ou florestais, com objetivos definidos e área delimitada, é chamado de queimada controlada. Já quando o fogo está descontrolado, consumindo toda ou parte de qualquer tipo de vegetação, é classificado como incêndio florestal (RIBEIRO; BONFIM, 2000; SOARES; BATISTA, 2007). 
Tanto as queimadas controladas quanto os incêndios florestais são uma das maiores ameaças à preservação da biodiversidade do planeta. Além dos seus impactos diretos sobre a fauna e a flora, contribuem, indiretamente, com a degradação ambiental, deixando o solo mais susceptível a processos erosivos e liberando na atmosfera grande quantidade de gases responsáveis pelo efeito estufa (SOARES; BATISTA, 2007; WHITE et al., 2013). Apesar de alguns ecossistemas terrestres, a exemplo do Cerrado Brasileiro e das Savanas Africanas, estarem adaptados e serem dependentes do fogo, a sua elevada frequência também é responsável por danos ambientais nessas comunidades ecológicas.

Todavia, é importante salientar que a técnica da queimada controlada se destaca pelo seu uso ao longo da história tendo participação na evolução do homem em função, principalmente, de seu baixo custo de aplicação, tendo em vista a rapidez e eficiência com que elimina material vegetal indesejável (RIBEIRO, 2009). Atualmente, a realização de queimadas controladas no Brasil é um tema polêmico e regido por legislação a níveis federais, estaduais e municipais. A nível federal, as queimadas são permitidas somente como fator de produção e manejo em atividades agropastoris e mediante prévia obtenção de autorização de órgão do Sistema Nacional do Meio Ambiente com atuação na área onde se realizará a operação (Decreto Federal $n^{\circ}$ 2.661/98), entretanto, nos últimos anos, alguns municípios passaram a proibi-las em função da poluição do ar com fuligem e problemas de saúde pública decorrentes. Em países como Estados Unidos, Austrália e Canadá, a queima controlada constitui uma das principais técnicas de prevenção de incêndios florestais de grande porte, à medida que contribuem com a redução do material combustível e consequente redução do risco.

Em Sergipe as queimadas controladas são geralmente realizadas de forma irregular, sem a requisição de autorização pela Administração Estadual do Meio-Ambiente (ADEMA). São frequentemente empregadas por grandes lavradores de cana-de-açúcar para facilitar o procedimento de colheita; por pecuaristas para estimular o nascimento de gramíneas; e por pequenos agricultores tradicionais como forma de limpeza de terreno. Entretanto, queimadas mal realizadas, em que o agricultor ou pecuarista, não tomando os devidos cuidados, acaba perdendo o controle do fogo que escapa a área delimitada e atinge demais regiões de forma descontrolada, compreendem uma das principais causas de ocorrência dos incêndios florestais no Brasil (SANTOS et al., 2006; SOARES, 2009). O fogo quando atinge áreas de conservação, torna-se ainda mais danoso ao meio ambiente, podendo, inclusive, levar determinadas espécies endêmicas e sensíveis ao fogo à extinção (DEBANO et al., 1998).

A detecção de queimadas e incêndios florestais através de satélites é uma tecnologia relativamente antiga, iniciada na década de 1980 (WANG et al., 2012). Em geral, a nível global, os satélites da série National Oceanic and Atmospheric Administration (NOAA), Advanced Very High Resolution Radiometer (AVHRR), e o Moderate Resolution Imaging Spectroradiometer (MODIS) são os mais utilizados. As imagens geradas pelos sensores termais e infravermelho instalados nestes satélites são enviadas para o centro de controle onde são processadas através de algoritmos de detecção (BATISTA, 2004; WANG et al., 2012). É essencial que seja empregado algum algoritmo já que um foco de calor não significa, necessariamente, que esteja ocorrendo uma queimada ou incêndio florestal, mas sim que um determinada área apresenta uma temperatura superior a $47^{\circ} \mathrm{C}$ (BATISTA, 2004). Apenas após tratamento, é possível identificar quais os focos de calor que representam fogo em vegetação, tornando-se possível a utilização destes dados para fins diversos, como combate ao fogo, estatísticas de emissão de carbono, delineamento de atividades preventivas, trabalhos científicos, dentre outros.

No Brasil, o Centro de Pesquisa do Tempo e Estudos Climáticos (CPTEC) do Instituto Nacional de Pesquisas Espaciais (INPE) gera e disponibiliza publicamente, via Internet, dados de focos de calor registrados por satélites e tratados por algoritmos que indicam apenas registros de fogo em vegetação, ou seja, incêndios florestais ou queimadas controladas. Apesar de receberem imagens de diversos satélites em operação (NOAA15, NOAA-16, NOAA-18, NOAA-19, NASA, TERRA, AQUA, GOES-12, GOES-13 e MSG-2), o "satélite de referência" é utilizado para compor a série temporal ao longo dos anos e assim, permitir a análise de tendências nos números de focos para mesmas regiões em períodos de interesse. De 1999 a agosto de 2007, o INPE utilizou o NOAA-12 como "satélite de referência", e a partir de então o AQUA_M-T. Mesmo indicando apenas uma fração do número real de focos, os dados do "satélite de referência" permitem analisar as tendências espaciais e temporais dos focos, já que utilizam o mesmo método e o mesmo horário para captura das imagens ao longo dos anos (INPE, 2016).

Apesar da detecção de fogo em vegetação via satélite possuir a vantagem de ter uma ampla abrangência, podendo recobrir grandes extensões de terra totalmente isoladas, limitações técnicas impedem que queimadas controladas ou incêndios de pequeno porte, geralmente com linha de frente do fogo com largura inferior a 50 metros, sejam detectados. Além disso, algumas situações como fogos que iniciaram e terminaram durante o intervalo de passagem dos satélites; presença de nuvens na área ardida; fogo superficial em vegetação com dossel fechado; e, fogo em encostas de montanhas enquanto o satélite só observou o outro lado, limitam a eficiência desta tecnologia. Portanto, o número de focos de calor registrado via satélite para uma determinada região corresponde apenas à uma fração do total de incêndios florestais e/ou queimadas controladas ocorridos (SETZER et al., 1992; PEREIRA et al., 2012; INPE, 2016). 
O presente trabalho tem por objetivo fazer uma análise dos focos de calor detectados pelos "satélites de referência" do INPE nos anos de 1999 a 2015, totalizando 17 anos, nos 75 municípios do estado de Sergipe. O mesmo se baseia na necessidade de informações acerca dos períodos e locais de ocorrência de incêndios florestais e queimadas controladas, assim como os fatores que contribuem para estas ocorrências, subsidiando assim a adoção de medidas preventivas de combate ao fogo.

\section{METODOLOGIA}

\section{Caracterização da área de estudo}

Sergipe é o menor dos estados Brasileiros, ocupando uma área total de 21.915,116 km² (IBGE, 2010). Está localizado na região Nordeste, fazendo limite com o oceano Atlântico a leste e os estados da Bahia, a oeste e a sul, e de Alagoas, a norte, do qual está separado pelo Rio São Francisco.

A região está situada nos domínios da Mata Atlântica e da Caatinga, separados por uma área de transição conhecida como Agreste, com a vegetação lembrando ora Caatinga, ora trechos de Mata Atlântica mais rala, que é na realidade uma Caatinga mitigada (CORDEIRO, 2008). O clima é tropical, mais úmido próximo ao litoral (pluviosidade média anual de $1600 \mathrm{~mm}$ na capital, com maior intensidade de chuvas entre março e julho) e semiárido no sertão.

\section{Obtenção dos dados de focos de calor}

Foram obtidos junto ao portal do INPE os dados referentes à ocorrência de focos de calor no estado de Sergipe, utilizando-se o satélite de referência, para o período de 01/01/1999 à 31/12/2015. Os valores foram quantificados e separados em função do mês de ocorrência e em função do município em que foi registrado.

\section{Fatores que influenciaram à ocorrência de incêndios e queimadas}

Dados referente à área de pastagem, área agrícola, área florestal e área total de todos os municípios do estado de Sergipe, além de suas respectivas precipitação anual média, foram obtidos junto à Secretaria Estadual de Meio Ambiente e Recursos Hídricos (SEMARH, 2010). Dados referente à população e densidade demográfica dos mesmos municípios foram obtidos junto ao Instituto Brasileiro de Geografia e Estatística (IBGE, 2010).

\section{Análise estatística}

A Análise de Variância (teste ANOVA) e o teste Tukey HDS foram utilizados para verificar a existência de diferença significativa entre o número de focos de calor registrados nos distintos meses do ano. A linha de tendência linear foi utilizada para demonstrar a expectativa de crescimento ou decréscimo do número de focos de calor para os próximos anos. O teste de correlação de Pearson (r) foi utilizado para verificar a existência de correlação significativa entre as variáveis independentes: área de pastagem, área agrícola, área florestal, precipitação anual média, população e densidade demográfica de cada município do estado de Sergipe; versus a variável dependente: número de focos de calor registrados em cada município. Em todas as análises o nível de significância adotado foi de $5 \%$.

É importante ressaltar que, apesar das variáveis área agrícola; área florestal; área de pastagem; população e densidade demográfica serem variáveis dinâmicas, ou seja, que podem apresentar mudanças de seus valores de ano para ano, foi verificada a existência de correlação apenas entre o número total de focos de calor registrados dentro de cada um dos 75 municípios versus os dados referentes ao ano de 2010 das respectivas variáveis dinâmicas acima mencionadas.

\section{RESULTADOS E DISCUSSÕES}

Ao todo, foram detectados 2600 focos de calor pelos satélites de referência em todo o estado de Sergipe entre 1999 e 2015, sendo o ano de 2000 com o menor número de focos e o ano de 2015 com o maior (Figura 2). A linha de tendência linear indica uma tendência significativa de alta no número de focos de calor para os próximos anos $\left(\mathrm{r}^{2}=0,33 ; \mathrm{p}=0,015\right)$.

Os meses com maior ocorrência de focos de calor foram, respectivamente, Janeiro, Fevereiro, Março, Dezembro, Novembro e Abril. Enquanto que os meses com menor ocorrência foram, respectivamente, Julho, Agosto, Junho, Setembro, Maio e Outubro. De acordo com o teste ANOVA, a ocorrência de focos de calor foi significativamente diferente entre os meses do ano $(\mathrm{F}=14,58 ; \mathrm{p}<0,01)$. O teste Tukey HDS classificou os meses em três grupos diferentes (A, B e C) (Figura 3). 


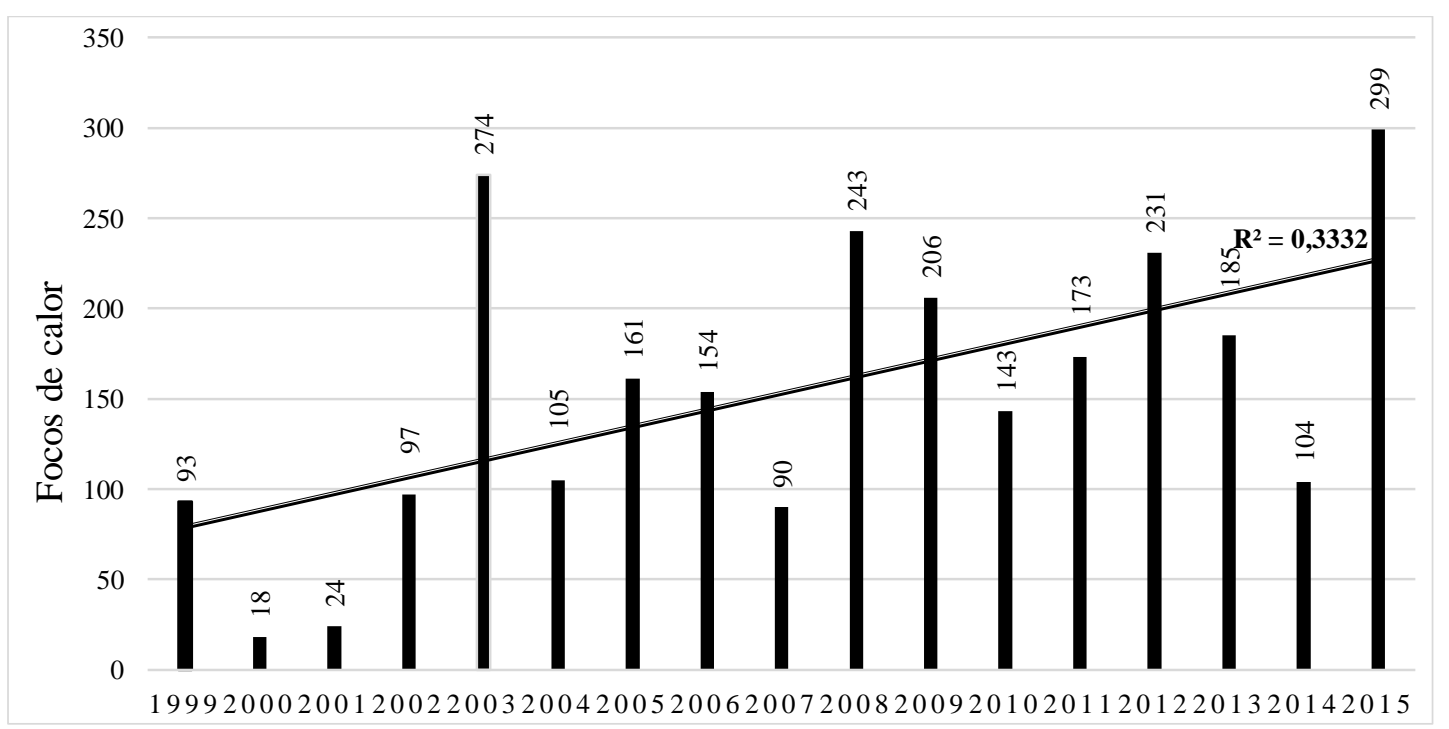

Figura 1. Registros de focos de calor no estado de Sergipe pelos satélites de referência do INPE entre os anos de 1999 a 2015. A linha indica a linha de tendência linear.

Figure 1. Hot spots detected by INPE's reference satellites between 1999-2015. The line indicates the linear tendency.

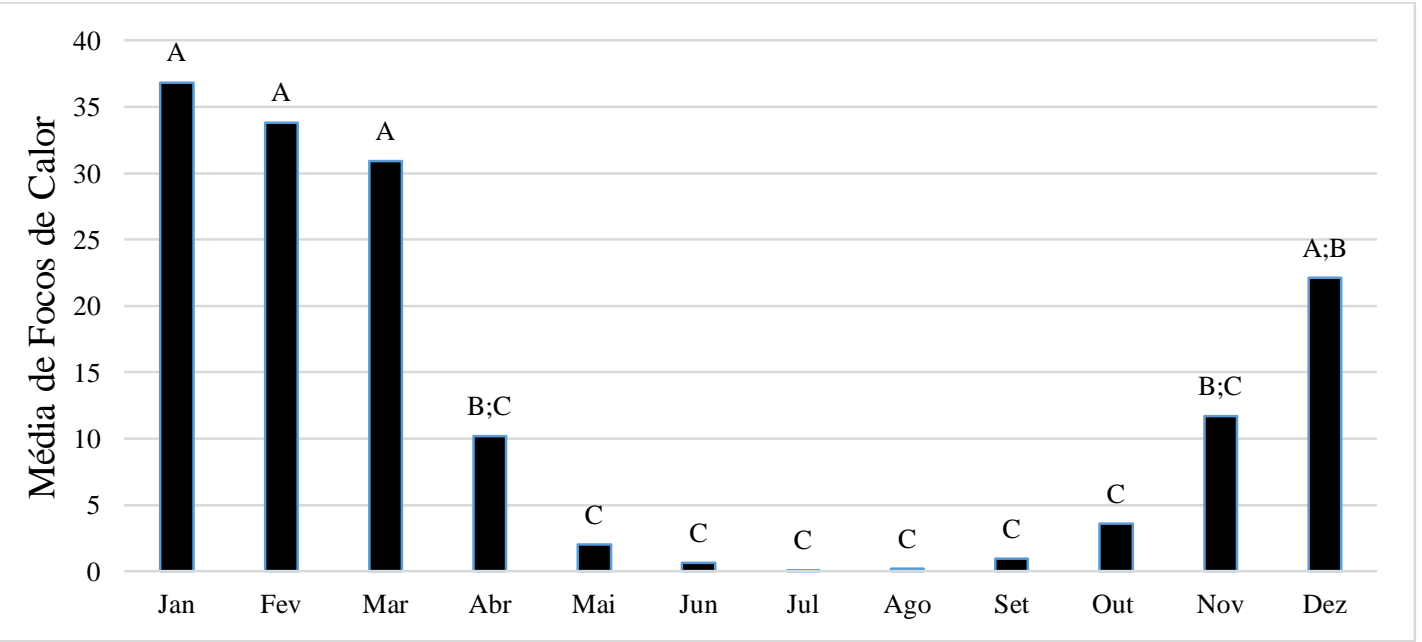

Figura 2. Média mensal de focos de calor registrados pelos satélites de referência do INPE entre 1999 e 2015 no estado de Sergipe. Os meses não agrupados com a mesma letra são significativamente diferentes com base no teste Tukey HDS.

Figure 2. Monthly hot spots mean registered by INPE's reference satellites between 1999 and 2015 in the state of Sergipe, Brazil. The months not grouped with the same letter are statically different based on the Tukey HDS test.

Este padrão de maior registro de queimadas controladas e incêndios florestais nos meses de Janeiro, Fevereiro e Março, difere da maioria dos demais estados Brasileiros. De acordo com Soares et al. (2005), Santos et al. (2006), Soares e Batista (2007) e Soares (2009), o período de Julho a Novembro compreende a principal estação de incêndios no Brasil, período este que, em grande parte do Brasil, é frio e seco. O estado de Sergipe está localizado em uma região denominada Zona da Mata, faixa costeira do Nordeste (até $300 \mathrm{~km}$ do litoral), que se estende do Rio Grande do Norte ao sul da Bahia, e que apresenta verão seco e inverno chuvoso (MOLION; BERNARDO, 2002; WHITE; RIBEIRO, 2011). Portanto, em função das baixas precipitações durante o verão, o material combustível se torna mais seco e, consequentemente, ocorre um aumento na incidência de incêndios florestais e queimadas. É relevante mencionar que, em função da grande extensão territorial do Brasil e, consequentemente, da diversidade de condições climáticas, existem demais regiões que também possuem seus períodos críticos de ocorrência de incêndios e queimadas distintos do padrão nacional. 
Foram registrados focos de calor em 74 das 75 unidades municipais do estado de Sergipe. Apenas no município de Pedrinhas não houve registro. O município com maior número de registros foi Tobias Barreto. A lista completa dos municípios e de suas respectivas áreas agrícolas, áreas de pastagens, áreas florestais, população, densidade demográfica, clima e precipitação média anual encontra-se descrita abaixo (Tabela 1).

Tabela 1. Municípios do estado de Sergipe e seus dados referentes ao número de focos de calor detectados; média anual de focos de calor; área total; relação área total dividida pela média de focos de calor por ano; área de pastagem; área agrícola; área florestal; população; densidade demográfica; e, precipitação média anual. Os municípios estão agrupados em ordem decrescente com relação à área total dividida pela média anual de focos.

Table 1. List of Sergipe's municipalities and their number of hot spots detected; mean annual hot spots; total area; total area divided by mean annual hot spots; pasture area; agriculture area; forestry area; population; population density and average annual rainfall. Municipalities are grouped in descending order of total area by mean annual hot spots rate.

\begin{tabular}{|c|c|c|c|c|c|c|c|c|c|c|c|}
\hline $\begin{array}{l}\text { Código } \\
\text { / Rank }\end{array}$ & Município & $\begin{array}{c}\text { Focos } \\
\text { de } \\
\text { calor }\end{array}$ & $\begin{array}{c}\text { Média } \\
\text { Focos } \\
\text { por ano }\end{array}$ & $\begin{array}{c}\text { Área } \\
\text { total } \\
\left(\mathbf{k m}^{2}\right) \\
\end{array}$ & $\begin{array}{c}\text { Área pela } \\
\text { média de } \\
\text { focos } \\
\left(\mathbf{k m}^{2}\right)\end{array}$ & $\begin{array}{c}\begin{array}{c}\text { Área de } \\
\text { pastagem } \\
\left(\mathbf{k m}^{2}\right)\end{array} \\
\end{array}$ & $\begin{array}{c}\text { Área } \\
\text { agrícola } \\
\left(\mathbf{k m}^{2}\right)\end{array}$ & $\begin{array}{c}\text { Área } \\
\text { florestal } \\
\left(\mathbf{k m}^{2}\right)\end{array}$ & População & $\begin{array}{c}\text { Densidade } \\
\text { demográfica } \\
\left(\mathbf{h a b} / \mathbf{k m}^{2}\right)\end{array}$ & $\begin{array}{c}\text { Precipitação } \\
\text { média anual } \\
(\mathbf{m m})\end{array}$ \\
\hline 1 & Canhoba & 57 & 3,35 & 170,29 & 51 & 166,06 & 0 & 24,03 & 3.956 & 23,20 & 1000 \\
\hline 2 & Maruim & 26 & 1,53 & 93,77 & 61 & 57,47 & 20,72 & 9,82 & 16.343 & 174,30 & 1600 \\
\hline 3 & Itabi & 47 & 2,76 & 184,42 & 67 & 191,33 & 0 & 26,19 & 4.972 & 27 & 1000 \\
\hline 4 & $\begin{array}{l}\text { São } \\
\text { Domingos }\end{array}$ & 26 & 1,53 & 102,47 & 67 & 56,67 & 14,18 & 16,51 & 10.271 & 100,20 & 1100 \\
\hline 5 & Laranjeiras & 39 & 2,29 & 162,28 & 71 & 57,63 & 63,74 & 22,89 & 26.902 & 165,80 & 1400 \\
\hline 6 & Aquidabã & 85 & 5,00 & 359,29 & 72 & 299,35 & 42,23 & 23,04 & 20.056 & 55,80 & 900 \\
\hline 7 & Neópolis & 62 & 3,65 & 265,95 & 73 & 136,07 & 80,28 & 16,67 & 18.506 & 69,60 & 1100 \\
\hline 8 & Riachuelo & 18 & 1,06 & 78,94 & 75 & 55,68 & 16,49 & 9,23 & 9.355 & 118,50 & 1500 \\
\hline 9 & $\begin{array}{l}\text { Cedro de } \\
\text { São João }\end{array}$ & 19 & 1,12 & 83,71 & 75 & 73,53 & 0 & 5,94 & 5.633 & 67,30 & 1000 \\
\hline 10 & $\begin{array}{l}\text { Amparo de } \\
\text { São } \\
\text { Francisco }\end{array}$ & 7 & 0,41 & 35,13 & 85 & 31,98 & 0 & 2,56 & 2.275 & 64,80 & 900 \\
\hline 11 & $\begin{array}{l}\text { Tobias } \\
\text { Barreto }\end{array}$ & 202 & 11,88 & $1.021,31$ & 86 & 541,79 & 204,07 & 171,48 & 48.04 & 47 & 900 \\
\hline 12 & $\begin{array}{l}\text { Santana do } \\
\text { São Francisco }\end{array}$ & 9 & 0,53 & 45,62 & 86 & 0 & 37,63 & 0,60 & 7.038 & 154,30 & 1100 \\
\hline 13 & $\begin{array}{l}\text { Divina } \\
\text { Pastora }\end{array}$ & 18 & 1,06 & 91,79 & 87 & 64,64 & 9,66 & 9,26 & 4.326 & 47,10 & 1600 \\
\hline 14 & Japoatã & 74 & 4,35 & 407,42 & 94 & 149,49 & 217,93 & 24,57 & 12.938 & 31,8 & 1200 \\
\hline 15 & $\begin{array}{l}\text { São Miguel } \\
\text { do Aleixo }\end{array}$ & 26 & 1,53 & 144,09 & 94 & 43,35 & 40,35 & 11,54 & 3.698 & 25,70 & 900 \\
\hline 16 & $\begin{array}{l}\text { Rosário do } \\
\text { Catete }\end{array}$ & 19 & 1,12 & 105,66 & 95 & 59,85 & 25,88 & 6,86 & 9.221 & 87,30 & 1600 \\
\hline 17 & $\begin{array}{l}\text { Riachão do } \\
\text { Dantas }\end{array}$ & 95 & 5,59 & 531,47 & 95 & 404,98 & 50,38 & 35,30 & 19.386 & 36,50 & 900 \\
\hline 18 & Pacatuba & 66 & 3,88 & 373,82 & 96 & 58,37 & 66,8 & 40,97 & 13.137 & 35,10 & 1300 \\
\hline 19 & $\begin{array}{l}\text { Malhada dos } \\
\text { Bois }\end{array}$ & 11 & 0,65 & 63,20 & 98 & 60 & 0,28 & 1,43 & 3.456 & 54,70 & 1000 \\
\hline 20 & Gararu & 109 & 6,41 & 654,99 & 102 & 486,58 & 0 & 119,64 & 11.405 & 17,40 & 800 \\
\hline 21 & $\begin{array}{l}\text { Gracho } \\
\text { Cardoso }\end{array}$ & 40 & 2,35 & 242,06 & 103 & 197,52 & 14,62 & 24,28 & 5.645 & 23,30 & 1000 \\
\hline 22 & $\begin{array}{l}\text { Santa Rosa } \\
\text { de Lima }\end{array}$ & 11 & 0,65 & 67,61 & 104 & 11,54 & 8,05 & 10,37 & 3.749 & 55,50 & 1500 \\
\hline 23 & Capela & 72 & 4,24 & 442,74 & 105 & 303,77 & 66,78 & 32,18 & 30.761 & 69,50 & 1100 \\
\hline 24 & Japaratuba & 59 & 3,47 & 364,90 & 105 & 123,60 & 143,54 & 35,92 & 16.864 & 46,20 & 1400 \\
\hline 25 & $\begin{array}{l}\text { Nossa } \\
\text { Senhora de } \\
\text { Lourdes }\end{array}$ & 13 & 0,76 & 81,06 & 106 & 76,83 & 0 & 5,22 & 6.238 & 77 & 800 \\
\hline 26 & Telha & 7 & 0,41 & 49,03 & 119 & 40,86 & 4,04 & 2,84 & 2.957 & 60,30 & 900 \\
\hline 27 & Lagarto & 130 & 7,65 & 969,58 & 127 & 707,2 & 184,46 & 123,08 & 94.861 & 97,80 & 1000 \\
\hline 28 & $\begin{array}{l}\text { Itaporanga } \\
\text { d`Ajuda } \\
\text { Nossa }\end{array}$ & 99 & 5,82 & 739,93 & 127 & 424,08 & 48,20 & 124,99 & 30.419 & 41,10 & 1500 \\
\hline 29 & $\begin{array}{l}\text { Senhora do } \\
\text { Socorro } \\
\text { Monte }\end{array}$ & 20 & 1,18 & 156,77 & 133 & 51,29 & 28,52 & 18,40 & 160.827 & $1.025,90$ & 1500 \\
\hline 30 & $\begin{array}{l}\text { Alegre de } \\
\text { Sergipe } \\
\text { Santo }\end{array}$ & 50 & 1,71 & 407,41 & 137 & 384,77 & 0 & 55,12 & 13.627 & 33,50 & 700 \\
\hline 31 & $\begin{array}{l}\text { Amaro das } \\
\text { Brotas }\end{array}$ & 29 & 2,94 & 234,16 & 139 & 36,65 & 61,89 & 63,79 & 11.41 & 48,70 & 1700 \\
\hline
\end{tabular}

FLORESTA, Curitiba, PR, v. 46, n. 4, p. 561 - 570, out. / dez. 2016.

White, B. L. A.; White, L. A. S.

ISSN eletrônico 1982-4688

DOI: $10.5380 /$ rf.v46i3.47036 


\begin{tabular}{|c|c|c|c|c|c|c|c|c|c|c|c|}
\hline 32 & Indiaroba & 38 & 2,24 & 313,53 & 140 & 114,47 & 93,83 & 66,20 & 15.831 & 50,50 & 1500 \\
\hline 33 & Estância & 78 & 4,59 & 644,08 & 140 & 371,45 & 41,59 & 90,92 & 64.409 & 100 & 1500 \\
\hline 34 & Siriri & 20 & 1,18 & 165,81 & 141 & 89,45 & 28,02 & 24,81 & 8.004 & 48,30 & 1500 \\
\hline 35 & $\begin{array}{l}\text { Nossa } \\
\text { Senhora das } \\
\text { Dores }\end{array}$ & 57 & 3,35 & 483,35 & 144 & 64,47 & 55,21 & 36,50 & 24.58 & 50,90 & 1100 \\
\hline 36 & Itabaianinha & 56 & 3,29 & 493,31 & 150 & 326,91 & 142,01 & 28,78 & 38.91 & 78,90 & 1100 \\
\hline 37 & Cristinápolis & 26 & 1,53 & 236,19 & 154 & 103,78 & 105,59 & 23,18 & 16.519 & 69,90 & 1500 \\
\hline 38 & Malhador & 11 & 0,65 & 100,94 & 156 & 17,06 & 32,81 & 16,26 & 12.042 & 119,30 & 1400 \\
\hline 39 & Porto da Folha & 88 & 5,18 & 877,30 & 169 & 780,67 & 0 & 156,89 & 27.146 & 30,90 & 700 \\
\hline 40 & Pirambu & 20 & 1,18 & 205,88 & 175 & 6,84 & 37,47 & 29,64 & 8.369 & 40,70 & 1400 \\
\hline 41 & $\begin{array}{l}\text { São } \\
\text { Cristóvão }\end{array}$ & 42 & 2,47 & 436,86 & 177 & 249,75 & 34,79 & 92,31 & 78.864 & 180,50 & 1500 \\
\hline 42 & $\begin{array}{l}\text { Moita } \\
\text { Bonita }\end{array}$ & 9 & 0,53 & 95,82 & 181 & 3,65 & 62,51 & 10,30 & 11.001 & 114,80 & 1200 \\
\hline 43 & $\begin{array}{l}\text { Tomar do } \\
\text { Geru }\end{array}$ & 28 & 1,65 & 304,90 & 185 & 201,47 & 82,21 & 25,44 & 12.855 & 42,20 & 1100 \\
\hline 44 & $\begin{array}{l}\text { Santa Luzia } \\
\text { do Itanhy }\end{array}$ & 29 & 1,71 & 325,73 & 191 & 153,28 & 57,21 & 83,63 & 12.969 & 39,80 & 1400 \\
\hline 45 & Macambira & 12 & 0,71 & 136,94 & 194 & 96,26 & 30,03 & 24,16 & 6.401 & 46,70 & 900 \\
\hline 46 & Frei Paulo & 34 & 2,00 & 400,36 & 200 & 269,39 & 11,09 & 35,91 & 13.874 & 34,70 & 900 \\
\hline 47 & Carira & 54 & 3,18 & 636,40 & 200 & 205,95 & 91,66 & 55,61 & 20.007 & 31,40 & 900 \\
\hline 48 & $\begin{array}{l}\text { Campo do } \\
\text { Brito }\end{array}$ & 17 & 1,00 & 201,73 & 202 & 137,19 & 25,74 & 15,22 & 16.749 & 83 & 1200 \\
\hline 49 & $\begin{array}{l}\text { São } \\
\text { Francisco }\end{array}$ & 7 & 0,41 & 83,85 & 204 & 68,44 & 10,83 & 3,07 & 3.393 & 40,50 & 1000 \\
\hline 50 & Pinhão & 13 & 0,76 & 155,89 & 204 & 117,04 & 13,61 & 35,32 & 5.973 & 38,30 & 1100 \\
\hline 51 & $\begin{array}{l}\text { Canindé de } \\
\text { São } \\
\text { Francisco }\end{array}$ & 75 & 4,41 & 902,25 & 205 & 819,5 & 14,90 & 254,1 & 24.686 & 27,4 & 600 \\
\hline 52 & $\begin{array}{l}\text { Areia } \\
\text { Branca }\end{array}$ & 12 & 0,71 & 146,68 & 208 & 61,87 & 20,56 & 53,44 & 16.857 & 114,90 & 1400 \\
\hline 53 & Ribeirópolis & 21 & 1,24 & 258,53 & 209 & 0,93 & 17,87 & 17,86 & 17.173 & 66,40 & 900 \\
\hline 54 & $\begin{array}{l}\text { Poço } \\
\text { Redondo }\end{array}$ & 97 & 5,71 & $1.232,12$ & 216 & 1109,61 & 42,12 & 234,18 & 30.88 & 25,10 & 600 \\
\hline 55 & Propriá & 7 & 0,41 & 92,46 & 225 & 39,95 & 42,49 & 3,37 & 28.451 & 319,20 & 900 \\
\hline 56 & Simão Dias & 40 & 2,35 & 564,70 & 240 & 363,80 & 124,94 & 75,84 & 38.702 & 68,50 & 900 \\
\hline 57 & Muribeca & 5 & 0,29 & 75,86 & 258 & 61,81 & 13,89 & 2,87 & 7.344 & 96,80 & 1100 \\
\hline 58 & Arauá & 13 & 0,76 & 198,75 & 260 & 143,26 & 32,53 & 12,80 & 10.878 & 54,70 & 1200 \\
\hline 59 & Salgado & 15 & 0,88 & 247,83 & 281 & 107,80 & 82,50 & 34,37 & 19.365 & 78,10 & 1400 \\
\hline 60 & $\begin{array}{l}\text { Ilha das } \\
\text { Flores }\end{array}$ & 3 & 0,18 & 54,64 & 310 & 0 & 35,30 & 1,18 & 8.348 & 152,80 & 1200 \\
\hline 61 & Cumbe & 7 & 0,41 & 128,60 & 312 & 103,86 & 18,10 & 7,33 & 3.813 & 29,70 & 1000 \\
\hline 62 & Feira Nova & 10 & 0,59 & 184,93 & 314 & 29,11 & 3,04 & 11,77 & 5.324 & 28,80 & 800 \\
\hline 63 & $\begin{array}{l}\text { Nossa } \\
\text { Senhora da } \\
\text { Glória }\end{array}$ & 40 & 2,35 & 756,49 & 322 & 477,53 & 0,84 & 52,32 & 32.497 & 43 & 700 \\
\hline 64 & Umbaúba & 6 & 0,35 & 118,86 & 337 & 26,50 & 76,11 & 5,05 & 22.434 & 188,80 & 1500 \\
\hline 65 & $\begin{array}{l}\text { General } \\
\text { Maynard }\end{array}$ & 1 & 0,06 & 19,98 & 340 & 7,82 & 7,72 & 1,36 & 2.929 & 146,60 & 1600 \\
\hline 66 & Boquim & 9 & 0,53 & 205,94 & 389 & 149,41 & 49,69 & 4,22 & 25.533 & 124 & 1300 \\
\hline 67 & Carmópolis & 2 & 0,12 & 45,91 & 390 & 30,9 & 8,92 & 1,57 & 13.503 & 294,20 & 1500 \\
\hline 68 & Poço Verde & 17 & 1,00 & 440,16 & 440 & 55,97 & 291,17 & 43,74 & 21.983 & 50 & 700 \\
\hline 69 & Itabaiana & 13 & 0,76 & 336,69 & 440 & 158,94 & 135,08 & 29,03 & 86.967 & 258,30 & 1000 \\
\hline 70 & $\begin{array}{l}\text { Nossa } \\
\text { Senhora } \\
\text { Aparecida }\end{array}$ & 13 & 0,76 & 340,38 & 445 & 0 & 2,92 & 9,89 & 8.508 & 25 & 800 \\
\hline 71 & Aracaju & 4 & 0,24 & 181,86 & 773 & 6,59 & 2,87 & 17,74 & 571.149 & $3.140,70$ & 1600 \\
\hline 72 & $\begin{array}{l}\text { Brejo } \\
\text { Grande }\end{array}$ & 3 & 0,18 & 148,86 & 844 & 0 & 40,31 & 20,64 & 7.742 & 52 & 1200 \\
\hline 73 & Pedra Mole & 1 & 0,06 & 82,03 & 1395 & 38,65 & 36,90 & 17,10 & 2.974 & 36,30 & 900 \\
\hline 74 & $\begin{array}{l}\text { Barra dos } \\
\text { Coqueiros }\end{array}$ & 1 & 0,06 & 90,32 & 1535 & 0,02 & 25,81 & 12,02 & 24.976 & 276,50 & 1600 \\
\hline 75 & Pedrinhas & 0 & 0,00 & 33,94 & - & 18,13 & 0 & 0,71 & 8.833 & 260,20 & 1100 \\
\hline
\end{tabular}

*Fonte: INPE, 2016; SEMARH, 2010; IBGE, 2010.

Dentre as variáveis analisadas, a área territorial dos municípios foi a que apresentou maior correlação com os focos de calor $(r=0,84 ; \mathrm{p}<0,001)$, seguida pela área de pastagem $(\mathrm{r}=0,75 ; \mathrm{p}<0,01)$, pela área florestal 
$(\mathrm{r}=0,72 ; \mathrm{p}<0,01)$, pela área agrícola $(\mathrm{r}=0,40 ; \mathrm{p}<0,01)$ e pela precipitação anual média $(\mathrm{r}=-0,27 ; \mathrm{p}=0,02)$. As variáveis densidade demográfica $(r=-0,17 ; \mathrm{p}=0,15)$ e população $(\mathrm{r}=0,02 ; \mathrm{p}=0,85)$ não apresentaram correlação significativa.

De acordo com White et al. (2016), o uso do solo através de explorações agropecuárias e florestais constituiu uma das principais variáveis que afetaram a ocorrência de incêndios florestais. A variável uso e cobertura do solo também foi associada à ocorrência de incêndios florestais em diversos outros trabalhos de mapeamento de áreas de maior risco (e.g. FIEDLER et al., 2006; ANDRADE et al., 2011; GONÇALVEZ et al., 2011; SURYABHAGAVAN et al., 2016; AJIN et al., 2016), sendo, normalmente, os sistemas agropecuários e pastagens definidos como de elevado risco.

Apesar da inexistência de correlação significativa entre a densidade demográfica e população dos municípios com o número de focos de calor, ambas as variáveis são constantemente citadas na literatura como um dos principais fatores afetando a incidência de incêndios florestais (e.g. CHUVIECO, 1997; OLIVEIRA et al., 2004; LIU et al., 2012; WHITE et al., 2016; SURYABHAGAVAN et al., 2016; AJIN et al., 2016). Considerando que $99 \%$ dos incêndios florestais ocorridos no Brasil se devem em função de atividades antrópicas (SOARES; BATISTA, 2007), há de se esperar que áreas com maior densidade demográfica tenham maior probabilidade de ocorrência de incêndios florestais. Entretanto, é necessário levar em conta que cidades densamente povoadas, normalmente, apresentam uma menor área de pastagem, agrícola e florestal, justamente, em função da ocupação do seu espaço com residências, estradas, áreas de comércio e lazer. Neste estudo, em particular, os municípios com maior densidade demográfica apresentaram, ainda que de forma não significativa, uma correlação negativa com a soma de suas respectivas áreas agrícolas, de pastagens e de florestais $(r=-0,16$; $p$ $=0,17$ ). Sendo assim, a inexistência de correlação entre população e densidade demográfica versus a quantidade de focos de calor registrada pode ser justificada, em parte, devido à menor disponibilidade de áreas agrícolas, de pastagens e florestais disponíveis para queimar.

Com base na relação entre a área total pela média anual de focos de calor registrados em cada município, foi desenvolvido um critério de classificação com o objetivo de agrupar os municípios com maior e menor incidência de queimadas controladas e incêndios florestais no estado de Sergipe nos últimos 17 anos. Os municípios que apresentaram uma média anual de um foco de calor para cada $75 \mathrm{~km}^{2}$ ou menos foram agrupados como tendo uma incidência "Muito Alta". Municípios classificados como de incidência "Alta", tiveram, uma média anual de um foco de calor para uma área entre 76 e $150 \mathrm{~km}^{2}$. Categorizados como de incidência "Média" estão os que apresentaram média anual de um registro de foco de calor para uma área entre 151 e $300 \mathrm{~km}^{2}$. No grupo de "Baixa" incidência, estão os municípios tiveram uma média anual de um foco de calor para uma área entre $301 \mathrm{~km}^{2}$ e $600 \mathrm{~km}^{2}$. Já na classe de incidência "Muito Baixa" estão os municípios com média anual de um foco de calor para cada 601 ou mais $\mathrm{km}^{2}$, além de Pedrinhas em que não houve nenhum registro (Figura 4). Esta metodologia de categorização está sendo proposta a fim de classificar e comparar a incidência de focos de calor em regiões com distintas áreas territoriais, tornando assim possível a comparação proporcional e um sistema de classificação padronizado. Portanto, futuros estudos que utilizem dos dados de focos de calor registrados pelos satélites de referência do INPE poderão categorizar as suas respectivas áreas avaliadas com base neste sistema de classificação.

O município de Canhoba (1) foi o que, proporcionalmente, registrou o maior número de focos de calor no estado de Sergipe. Além de Canhoba, outros 08 municípios, enumerados de 2 a 9 (Tabela 1), apresentaram elevado registro de focos de calor por área e foram classificados como de incidência "Muito Alta". Os municípios enumerados de 10 a 36 foram classificados como de incidência "Alta". Já os municípios de 37 a 59 foram classificados como de incidência "Média". Os enumerados de 60 a 70 foram agrupados como de incidência "Baixa", apresentando maior registro por área apenas que municípios de 71 a 75, rotulados como de incidência "Muito Baixa".

Os dados apresentados neste estudo e a classificação acima proposta também podem ser utilizados a fim de estimar o risco futuro de ocorrência de incêndios florestais e queimadas nos distintos municípios do estado de Sergipe, sendo o mapa apresentado na figura 4, também podendo ser interpretado como um mapa de Risco. Embora a construção de mapas de risco de fogo geralmente envolva o uso de diversas variáveis ambientais (a exemplo do relevo, vegetação e condições climáticas) e humanas (a exemplo da densidade demográfica, uso do solo, distância dos povoados, distância das estradas, dentre outras) (CHUVIECO, 1997; WHITE et al., 2016; SURYABHAGAVAN et al., 2016; AJIN et al., 2016), a análise da distribuição espacial das ocorrências também é, comprovadamente, um critério bastante importante no mapeamento do risco de fogo em vegetação (CHUVIECO, 1997) e utilizada, direta ou indiretamente, por diversos autores (e.g. CHUVIECO; SALAS, 1996; DÍAZ-DELGADO et al., 2004; LIU et al., 2012; WHITE et al., 2016).

O mapeamento de áreas com maior incidência de incêndios florestais e queimadas controladas, portanto, além de poder indicar áreas com maior ou menor risco futuro de incidência, torna possível a sobreposição dessas informações com diversos outros mapas temáticos, utilizando-se de Sistemas de Informação

FLOREST A, Curitiba, PR, v. 46, n. 4, p. 561 - 570, out. / dez. 2016.

White, B. L. A.; White, L. A. S.

ISSN eletrônico 1982-4688

DOI: $10.5380 /$ rf.v46i3.47036 
Geográfica (SIG), que permitem a interpretação dos fatores responsáveis pela a ocorrência do fogo na vegetação (DÍAZ-DELGADO et al., 2004), aumentando assim o conhecimento e facilitando o desenvolvimento de planos de prevenção e de conservação pós-fogo.

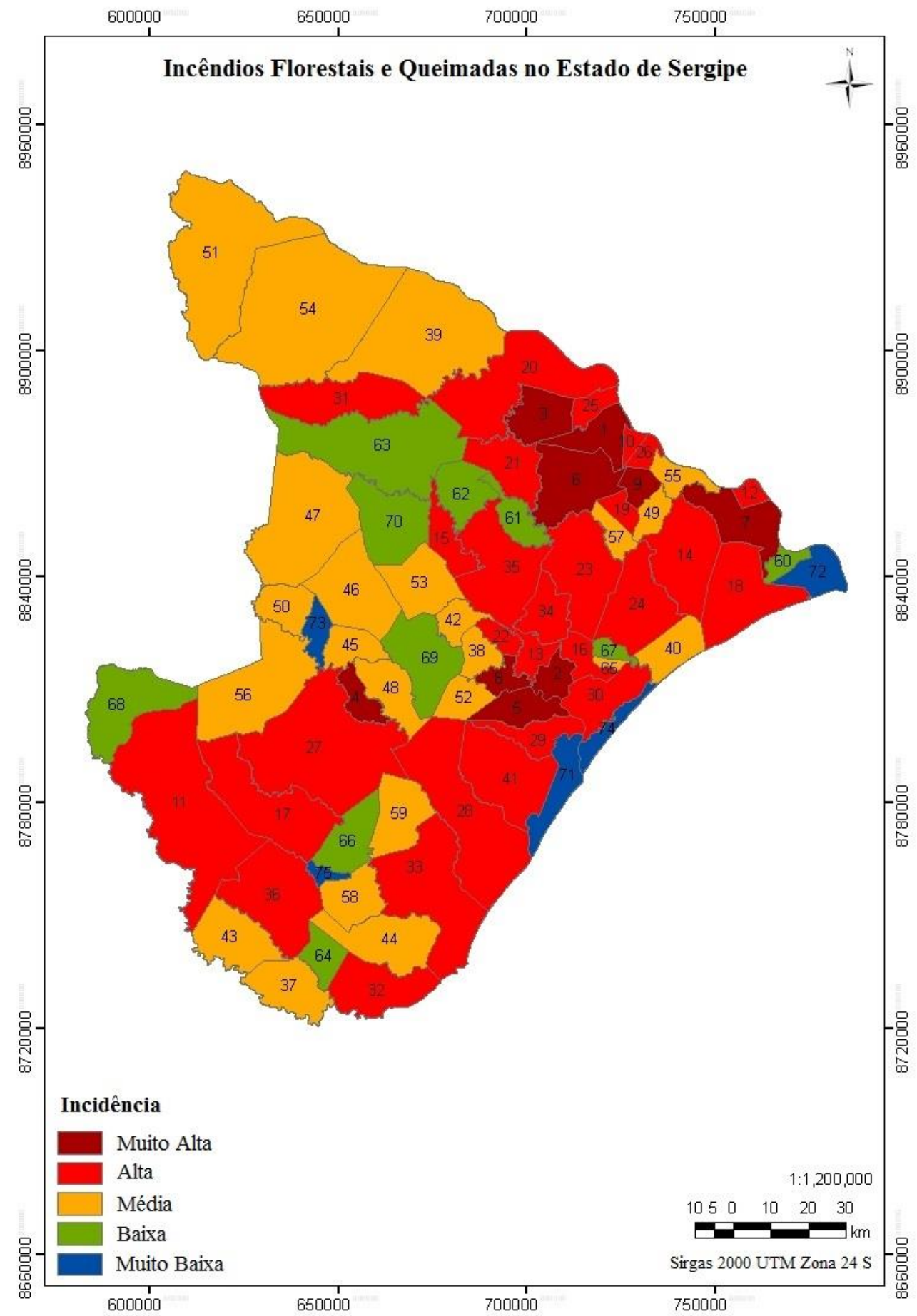

Figura 3. Categorização da frequência de incidência de queimadas e incêndios florestais nos municípios do estado de Sergipe com base na média anual de focos de calor por quilômetro quadrado detectados pelos satélites de referência do INPE entre os anos de 1999 a 2015.

Figure 3. Categorization of Sergipe's municipalities according wildland fire occurrence based on data of mean annual number of hot spots per square kilometer detected by INPE's reference satellites between $1999-2015$. 


\section{CONCLUSÕES}

- Ao todo, foram detectados 2600 focos de calor pelo satélite de referência do INPE em todo o estado de Sergipe entre 1999 e 2015. Janeiro, Fevereiro e Março foram os meses com maior registro de focos de calor; os meses de Abril, Novembro e Dezembro apresentaram valores intermediários; e, os meses de Maio, Junho, Julho, Agosto, Setembro e Outrubro tiveram um menor registro.

- Tobias Barreto foi o município Sergipano que apresentou um maior número de focos de calor, no entanto, os municípios de Canhoba, Maruim, Itabi, São Domingos, Laranjeiras, Aquidabã, Neópolis, Riachuelo, Cedro de São João e Amparo de São Francisco apresentaram, em ordem decrescente, mais focos por área.

- Dentre as variáveis independentes analisadas, a área total do município, área de pastagem, área florestal, área agrícola e precipitação anual média apresentaram, em ordem decrescente de significância, correlação significativa com o número de registro de focos de calor para cada município. As variáveis população e densidade demográfica não apresentaram correlação significativa.

- Com base nos resultados advindos deste estudo foi possível verificar quais as regióes do estado que apresentaram uma maior incidência de focos de calor. É importante ressaltar que os números apresentados neste trabalho não indicam o montante total de incêndios e queimadas controladas que realmente ocorreram durante o período, já que existem limitações na detecção de incêndios e queimadas por satélites. No entanto, os registros permitem analisar as tendências espaciais e temporais, podendo, portanto, serem utilizados como critério para análise de risco futuro e delineamento de ações preventivas.

\section{AGRADECIMENTOS}

À FAPITEC/SE e ao CNPq pelo financiamento desta pesquisa.

\section{REFERÊNCIAS}

AJIN, R. S.; LOGHIN, A. M.; JACOB, M. K.; VINOD, P. G.; KRISHNAMURTHY, R. R. The Risk Assessment Study of Potential Forest Fire in Idukki Wildlife Sanctuary using RS and GIS Techniques. International Journal of Advanced Earth Science and Engineering, [S.1], v. 5, n. 1, p. 308-318, 2016.

ANDRADE, C. F.; RIBEIRO, G. A.; GLERIANI, J. M.; MARTINS, M. C. Uso de fotografias aéreas não convencionais e SIG na elaboração de mapas de risco de incêndios florestais. In: SIMPÓSIO BRASILEIRO DE SENSORIAMENTO REMOTO, 15., 2011, São José dos Campos. Anais... Curitiba: INPE, p. 7918-7925, 2011.

BATISTA, A. C. Detecção de incêndios florestais por satélites. Floresta, Curitiba, v. 34, n. 2, p. 237-241, 2004.

CHUVIECO, E. A review of remote sensing methods for the study of large wildland fires. Alcalá de Henares, Spain: Universidad de Alcalá, 1997.

CHUVIECO, E.; SALAS, J. Mapping the spatial distribution of forest fire danger using GIS. International Journal of Geographical Information Science, [S.1], v. 10, n. 3, p. 333-345, 1996.

CORDEIRO, J. C. Diagnóstico da biodiversidade de vertebrados terrestres de Sergipe. $2008,148 \mathrm{f}$. Dissertação (Mestrado em Desenvolvimento e Meio Ambiente) - Núcleo de Pós-Graduação em Desenvolvimento e Meio Ambiente, Pró-Reitoria de Pós-Graduação e Pesquisa, Universidade Federal de Sergipe, 2008.

DEBANO, L. F.; NEARY, D. G.; FFOLLIOTT, P. F. Fire's Effects on Ecosystems. New York: John Wiley \& Sons, $1998,335 \mathrm{p}$.

DÍAZ-DELGADO, R.; LLORET, F.; PONS, X. Spatial patterns of fire occurrence in Catalonia, NE, Spain. Landscape Ecology, [S.1], v. 19, n. 7, p. 731-745, 2004.

FIEDLER, N. C.; MERLO, D. A.; MEDEIROS, M. B. de. Ocorrência de incêndios florestais no Parque Nacional da Chapada dos Veadeiros, Goiás. Ciência Florestal, Santa Maria, v. 16, n. 2, p. 153-161, 2006.

GONÇALVES, C. N.; MESQUITA, F. W.; LIMA, N. R. G.; COSLOPE, L. A.; LINTOMEN, B. S. Recorrência dos incêndios e fitossociologia da vegetação em áreas com diferentes regimes de queima no Parque Nacional da Chapada Diamantina. Revista Biodiversidade Brasileira, [S.1.], v. 1, n. 2, p. 161-179, 2011.

INSTITUTO BRASILEIRO DE GEOGRAFIA E ESTATÍSTICA (IBGE). Cidades - Sergipe. 2010. Disponível em: <http://www.cidades.ibge.gov.br/download/mapa_e_municipios.php?lang=\&uf=se> Acesso em: 28/04/2016. 
INSTITUTO NACIONAL DE PESQUISAS ESPACIAIS (INPE). Portal do Monitoramento de Queimadas e Incêndios. 2016. Disponível em: <http://www.inpe.br/queimadas> Acesso em: 28/04/2016.

LIU, Z.; YANG, J.; CHANG, Y.; WEISBERG, P. J.; HE, H. S. Spatial patterns and drivers of fire occurrence and its future trend under climate change in a boreal forest of Northeast China. Global Change Biology, [S.1], v. 18, n. 6, p. 2041-2056, 2012.

MOLION, L. C. B.; BERNARDO, S. O. Uma revisão da dinâmica das chuvas no nordeste brasileiro. Revista Brasileira de Meteorologia, São Paulo, v. 17, n. 1, p. 1-10, 2002.

OLIVEIRA, D. S.; BATISTA, A. C.; SOARES, R. V.; GRODZKI, L.; VOSGERAU, J. Zoneamento de risco de incêndios florestais para o Estado do Paraná. Floresta, Curitiba, v. 34, n. 2, p. 217-221, 2004.

PEREIRA, A. A.; PEREIRA, J. A. A.; MORELli, F.; BARROS, D. A.; ACERBI JUNIOR, F. W.; SCOLFORO, J. R. S. Validação de focos de calor utilizados no monitoramento orbital de queimadas por meio de imagens TM. Cerne, Lavras, v. 18, n. 2, p. 335-343, 2012.

RIBEIRO, G. A. A queima controlada no manejo da terra. In: SOARES, R. V.; BATISTA, A. C.; NUNES, J. R. S. (Ogs.) Os incêndios Florestais no Brasil: o estado da arte. Curitiba: UFPR, p. 181-214, 2009.

RIBEIRO, G. A.; BONFIM, V. R. Incêndio Florestal versus queima controlada. Ação Ambiental, Viçosa, v. 2, n. 12 , p. $8-11,2000$.

SANTOS, J. F.; SOARES, R. V.; BATISTA, A. C. Perfil dos Incêndios florestais no Brasil em áreas protegidas no período de 1998 a 2002. Floresta, Curitiba, v. 36, n. 1, p. 93-100, 2006.

SETZER, A.; PEREIRA, M. C.; PEREIRA JR, A. C. O uso de satélites NOAA na detecção de queimadas no Brasil. Climanálise, [S.1], v. 7, n. 8, p. 40-53, 1992.

SOARES, R. V. Estatística dos incêndios florestais no Brasil. In: SOARES, R. V.; BATISTA, A. C.; NUNES, J. R. S. (Eds.) Incêndios florestais no Brasil: o estado da arte. Curitiba: UFPR, p. 1-20, 2009.

SOARES, R. V.; BATISTA, A. C. Incêndios Florestais: controle, efeitos e uso do fogo. Curitiba: UFPR, 2007. $264 \mathrm{p}$.

SOARES, R. V.; BATISTA, A. C.; SANTOS, J. F. Evolução do perfil dos incêndios florestais em áreas protegidas no Brasil, de 1983 a 2002. In: SEMINÁRIO DE ATUALIDADES EM PROTEÇÃO FLORESTAL, 2., 2005, Blumenau, SC. Anais... Curitiba: UFPR/FURB/FUPEF, 2005. v. 1. p. 1-10.

SURYABHAGAVAN, K. V.; ALEMU, M.; BALAKRISHNAN, M. GIS-based multi-criteria decision analysis for forest fire susceptibility mapping: a case study in Harenna forest, southwestern Ethiopia. Tropical Ecology, [S.1], v. 57, n. 1, p. 33-43, 2016.

WANG, S. D.; MIAO, L. L.; PENG, G. X. An Improved Algorithm for Forest Fire Detection Using HJ Data. Procedia Environmental Sciences, [S.1.], v. 13, p. 140-150, 2012.

WHITE, B. L. A.; RIBEIRO, A. S. Análise da precipitação e sua influência na ocorrência de incêndios florestais no Parque Nacional Serra de Itabaiana, Sergipe, Brasil. Ambi-Agua, Taubaté, v. 6, n. 1, p. 148-156, 2011.

WHITE, B. L. A.; WHITE, L. A. S.; RIBEIRO, G. T.; FERNANDES, P. A. M. Development of a fire danger index for Eucalypt plantations in the northern coast of Bahia, Brazil. Floresta, Curitiba, v. 43, n. 4, p. 601-610, 2013.

WHITE, L. A. S.; WHITE, B. L. A.; RIBEIRO, G. T. Modelagem especial do risco de incêndio florestal para o município de Inhambupe, BA. Pesquisa Florestal Brasileira, Colombo, v. 36, n. 85, p. 41-49, 2016. 